\title{
A rapid determination of chloride in saturated paste extracts of salt-affected soils using EC change upon AgCl precipitation
}

\author{
Yehun Lee ${ }^{1} \cdot$ Jeeyoon Kim ${ }^{1} \cdot$ Jeongsu Lee ${ }^{1} \cdot$ Khok Pros $^{1} \cdot$ Jee Won Park $^{2}$. \\ Gwang Hyun Han ${ }^{1}$ iD
}

\section{$\mathrm{AgCl}$ 침전 전후 전기전도도 변화를 이용한 염해지 포화침출액의 염소 이온 신속 정량}

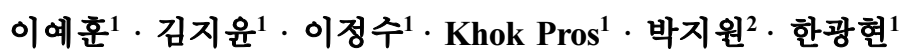

Received: 27 July 2017 / Accepted: 3 September 2017 / Published Online: 30 September 2017

(C) The Korean Society for Applied Biological Chemistry 2017

\begin{abstract}
Chloride is known as the most important anion in saltaffected soils. We observed the degree of EC change upon $\mathrm{AgCl}$ precipitation was quantitatively related with the chloride concentration. Method validation and intercomparison with ion chromatography revealed the proposed method can provide rapid and moderately precise chloride concentrations in salt-affected soils.
\end{abstract}

Keywords Argentometry · High-throughput analysis · Interfering ions $\cdot$ Ion chromatography $\cdot$ Saline soils

\section{서 론}

토양의 염류 집적은 안정적인 식량 생산을 저해하는 가장 큰 요소들 중 하나이며, 전 세계 경작 가능한 면적의 $10 \%$ 이상이

Gwang Hyun Han $(\bowtie)$

E-mail: hangh@cbnu.ac.kr

${ }^{1}$ Department of Environmental and Biological Chemistry, Chungbuk National University, Cheongju, Chungbuk 28644, Republic of Korea

${ }^{2}$ Technel Co., Ltd, 407, Seoul TechnoPark 232, Gongreung-ro, Nowon-Gu, Seoul 01811, Republic of Korea

This is an Open Access article distributed under the terms of the Creative Commons Attribution Non-Commercial License (http://creativecommons. org/licenses/by-nc/3.0/) which permits unrestricted non-commercial use, distribution, and reproduction in any medium, provided the original work is properly cited. 염류성(saline) 혹은 나트륨성(sodic) 토양으로 분류된다(Leland 와 Eugene 1999; Rengasamy 2006). 염해토양은 주로 건조 혹 은 반건조대에 분포할 것으로 여겨지나, 남극을 제외한 모든 기 후대와 100 개 국 이상에 걸쳐 발견된다(Rengasamy 2010). 한 국에서 염해토양은 과다시비된 시설재배지와 바다를 매립해 조 성된 간척지를 위주로 분포하고 있다(Lee 등, 2010; Lee 등, 2012). 이러한 염류집적지의 염도 변화 모니터링은 비교적 세밀 한 조제 과정을 거쳐 얻어지는 포화침출액(saturated paste extract)에 대해 $\mathrm{EC}$ 및 구성 양이온 혹은 음이온들을 분석하는 방법이 표준으로 사용된다(Rhoades 1996; Herrero 등, 2015). $\mathrm{Na}^{+}$가 작물생육 저해에 가장 큰 영향을 미치는 양이온이라면 (Wong 등, 2010), $\mathrm{Cl}^{-}$는 염해지 식물독성에 가장 밀접하게 관 련된 음이온으로 알려져 있다(Xu 등, 1999). $\mathrm{Cl}^{-}$는 식물의 광합 성, 전하 균형 및 삼투압 조절에 필수이지만(White와 Broadley 2001), 조직 내 높은 $\mathrm{Cl}^{-}$농도는 엽록소 파괴, 세포막 손상, 효 소 활성 저해 등의 독성을 유발한다(Tavakkoli 등, 2010).

토양 추출액 중 $\mathrm{Cl}^{-}$의 정량은 이온 선택성 전극 혹은 지시약 을 이용한 적정법, $\mathrm{Hg}(\mathrm{SCN})_{2}$ 을 이용한 발색 분광법, 이온선택 성 전극에 의한 직접 측정, 이온 크로마토그래피 등 다양한 방 법들이 적용될 수 있지만(Tabatabai와 Frankenberger 1996), 각 기 적정 종말점 결정의 어려움, 유독성 물질의 취급, 방해 이온 들의 간섭, 정교한 사전 보정, 고가의 분석장비 요구 등의 단점 들이 고려되어야 한다(Frankenberger 등, 1996). 아울러, 이온 크로마토그래피는 상대적으로 가장 높은 감도와 정밀도를 제공 하지만 비교적 좁은 농도 구간(일반적으로 $100 \mathrm{ppm}$ 이하)에서 적용 가능하다. 따라서, $\mathrm{Cl}^{-}$농도가 수천 $\mathrm{ppm}$ 을 상회할 수 있 는 염해토양 추출액의 경우(Jung과 Yoo 2007), 과도한 희석 및 시행착오를 통한 희석비 결정이 추가적으로 단점이 된다. 한편, 
최근 저자들은 기존 방법들과 달리, 용액 중 $\mathrm{Cl}^{-}$가 $\mathrm{Ag}^{+}$와 결합 하여 침전될 때 수반되는 전기전도도 변화를 $\mathrm{EC}$ 전극으로 간 단히 측정함으로써 $\mathrm{Cl}^{-}$의 정량이 가능함을 처음으로 보고한 바 있다(Boo 등, 2015). 이 $\mathrm{AgCl}$ 침전 전기전도도차(Ag-dEC)법은 정밀한 기기분석법이나 전위차 적정법에 비해 상대적으로 낮은 감도와 정밀도를 보일 수 있으나, $\mathrm{Cl}^{-}$의 농도가 높은 염해지의 염도 분포 및 변화 모니터링에 적합할 것으로 기대된다.

이에 본 연구는 $\mathrm{Ag}-\mathrm{dEC}$ 방법의 (1) 검출한계, 정량한계, 정 밀도 및 감도가 염해토양의 $\mathrm{Cl}^{-}$정량 목적에 부합할 수 있는 지 조사하였으며, (2) 전남 고흥 간척지에서 채취된 토양의 포 화침출액 대해 이온 크로마토그래피로 분석된 결과와 비교함으 로써, 이 새로운 방법의 염해지 염도 분포 및 모니터링에 대한 적용성을 평가하고자 하였다.

\section{재료 및 방법}

\section{표준 용액 및 시약}

$\mathrm{Cl}^{-}$표준용액 (1,000 ppm, $\left.\mathrm{NaCl}\right)$ 은 Merk (Darmstadt, Germany), EC 표준용액 $\left(1,413 \mu \mathrm{S} \mathrm{cm}^{-1}, \mathrm{KCl}\right)$ 은 Horiba (Ubi crescent, Singapore)의 제품을 사용하였다. $\mathrm{AgNO}_{3}$ (99.8\%)는 Samchun (Pyeongtaek, Korea)으로부터 구입하였다.

\section{$\mathrm{Ag}-\mathrm{dEC}$ 법의 검량선}

3 차 탈이온수로 희석하여 제조된 $100,200,300,400,500$ $\mathrm{ppm}$ 의 $\mathrm{Cl}^{-}$표준용액 $1 \mathrm{~mL}$ 를 $15 \mathrm{~mL} \mathrm{PP}$ 재질 튜브에 옮기고, $0.15 \%(\mathrm{v} / \mathrm{v})$ 아세트산 $1 \mathrm{~mL}$ 와 탈이온수 $400 \mu \mathrm{L}$ 를 첨가하고 볼 텍싱한 다음, EC 전극( $013605 \mathrm{MD}$, Thermo Scientific, Waltham, $\mathrm{MA}, \mathrm{USA})$ 으로 전기전도도를 측정하였다. 이 측정값을 $\mathrm{EC} \_\mathrm{A}$ 라 하고, 동일하게 준비된 표준용액에 탈이온수 대신 $35 \mathrm{mM}$ $\mathrm{AgNO}_{3} 400 \mu \mathrm{L}$ 를 처리하여 측정된 전기전도도를 $\mathrm{EC} B$ 라고 하 면, $\mathrm{AgCl}$ 침전 전후의 전기전도도 차는 다음과 같이 정의된다.

$$
\mathrm{dEC}=\mathrm{EC} \_\mathrm{A}+\mathrm{EC} \_\mathrm{C}-\mathrm{EC} \_\mathrm{B}
$$

여기서 $\mathrm{EC} \_\mathrm{C}$ 는 순수하게 가해진 $\mathrm{AgNO}_{3}$ 만의 전기전도도로, 탈이온수 $2 \mathrm{~mL}$ 에 $35 \mathrm{mM} \mathrm{AgNO} 3400 \mu \mathrm{L}$ 를 가한 후 측정된 값으로 하였다. 아세트산은 시료에 존재하는 인산 및 탄산이온 이 $\mathrm{Ag}^{+}$와 침전하는 것을 방지하는 역할을 한다(Boo 등, 2015). 검량선은 측정된 $\mathrm{dEC}$ 와 $\mathrm{Cl}^{-}$농도 간 선형회귀로 작성하였다.

\section{분석법 검중}

검출한계와 정량한계는 $1.0 \mathrm{ppm}$ 표준용액을 8 반복 측정하여 얻은 $\mathrm{dEC}$ 측정값들과 검량선을 통해 구하였다. 한편, 정밀도는 검출한계의 10 배 수준에서 얻어진 $\mathrm{dEC}$ 측정값들의 상대표준편 차로부터 구하였다.

\section{토양 시료 채취 및 포화침출액 제조}

2016년 9월, 전남 고흥군 도덕면과 고흥읍 간척지 일원 17개 필지에서 상층부 $(0-30 \mathrm{~cm})$ 토양을 오거로 채취하여 풍건하였다. 염해토양들의 화학성은 농진청 토양분석법(NIAST 2000)에 준
Table 1 Chemical properties of the examined salt-affected soils $(n=17)$

\begin{tabular}{cccccc}
\hline \hline & $\mathrm{pH}$ & $\begin{array}{c}{ }^{\mathrm{a}} \mathrm{EC}_{\mathrm{e}} \\
\left(\mathrm{dS} \mathrm{m}^{-1}\right)\end{array}$ & $\begin{array}{c}{ }^{\mathrm{b}} \mathrm{OM} \\
(\%)\end{array}$ & $\begin{array}{c}{ }^{\mathrm{c}} \mathrm{CEC} \\
\left(\mathrm{cmol}_{\mathrm{c}} \mathrm{kg}^{-1}\right)\end{array}$ & ${ }^{\mathrm{d}} \mathrm{SAR}$ \\
\hline Mean & 8.4 & 3.8 & 0.6 & 17.1 & 3.3 \\
Min & 7.3 & 0.7 & 0.1 & 8.1 & 1.4 \\
Max & 9.2 & 9.6 & 1.4 & 30.4 & 6.3 \\
SD & 0.4 & 2.1 & 0.4 & 7.4 & 1.6 \\
\hline
\end{tabular}

${ }^{\mathrm{a}} \mathrm{ECe}$ is electrical conductivity of soil saturated paste extract.

${ }^{\mathrm{b}} \mathrm{OM}$ is organic matter content.

${ }^{\circ} \mathrm{CEC}$ is cation exchange capacity.

${ }^{\mathrm{d}} \mathrm{SAR}$ is sodium adsorption ratio $\left(\left[\mathrm{Na}^{+}\right] /\left(\left(\left[\mathrm{Ca}^{2+}\right]+\left[\mathrm{Mg}^{2+}\right]\right) / 2\right)^{0.5}\right)$.

해 결정되었으며, Table 1에 제시되어 있다. $2 \mathrm{~mm}$ 채를 통과한 풍건 토양 $250 \mathrm{~g}$ 을 $300 \mathrm{~mL}$ 스테인레스 용기에 옮기고, 증류수 를 서서히 가하면서 포화반죽 상태에 이르도록 시료를 혼합하 였다. 약 16시간 동안 평형처리한 후, Whatman 50 여과지로 진공 흡입 여과하였다(Rhoades 1996).

\section{포화침출액의 $\mathbf{C l}^{-}$정량 및 통계분석}

동일한 포화침출액 시료에서 일부를 취하여 $\mathrm{Ag}-\mathrm{dEC}$ 법과 이온 크로마토그래프(861, Metrohm, Herisau, Switzerland)로 각각 $\mathrm{Cl}^{-}$을 정량하였다. 각 분석방법에 대한 검량선의 최대 농도가 100 과 $500 \mathrm{ppm}$ 으로 상이하였기 때문에, 측정 범위를 넘어서는 시료들의 경우 각기 다른 희석비가 적용되었다. 아울러, 두 측 정법의 분석결과들 간에 유의한 차이가 있는지 확인하기 위해, 대응 표본 t 검정(paired t test; Harris 2007)을 Microsoft Excel ${ }^{\circledR}$ 이용하여 실시하였다.

\section{결과 및 고찰}

\section{$\mathrm{Ag-dEC}$ 분석법 정립: 검량선 및 감도}

용액 중 $\mathrm{Cl}^{-}$이 $\mathrm{AgCl}$ 로 침전될 때 수반되는 전기전도도 변화도 $(\mathrm{dEC})$ 는 염소 이온 농도(최대 $500 \mathrm{ppm}$ 농도 구간)와 매우 정량 적이고 직선적인 관계가 있음이 확인되었다(Fig. 1). 검량선의 기울기로 파악되는 분석감도 역시 $1.6 \mu \mathrm{S} \mathrm{cm}^{-1} \mathrm{ppm}^{-1}$ 로 양호하 였다. 일반적으로 $\mathrm{EC}$ 메터의 에러는 $1.0 \mu \mathrm{S} \mathrm{cm}^{-1}$ 보다 크지 않고 (Rhoades 1996), 측정 범위 역시 $10,000 \mu \mathrm{S} \mathrm{cm}^{-1}$ 보다 넓기 때문 에, 제안된 $\mathrm{Ag}-\mathrm{dEC}$ 법은 비교적 높은 $\mathrm{Cl}^{-}$농도를 가지는 시료 들의 분석에 적합하다고 여겨진다. 분석 용액에 공존하는 인산 이온 및 탄산이온의 방해효과는 분석과정 중에 첨가된 아세트 산에 의해 용액의 $\mathrm{pH}$ 가 4 부근으로 유지됨으로써 제거되지만 (Boo 등, 2015), 용액 중 $\mathrm{Br}^{-}$와 $\mathrm{I}^{-}$는 잠재적으로 $\mathrm{Cl}^{-}$의 정량에 직접적이고 심각한 간섭효과를 줄 수 있다. 하지만, 이들의 토 양 중 농도는 $\mathrm{Cl}^{-}$에 비해 무시할 수 있는 수준으로 낮은 것으 로 알려져 있다(Frankenberger 등, 1996). 해수의 영향이 큰 간 척지의 경우에도 이 두 방해 이온의 농도는 높지 않은 것으로 보고된 바 있다(Jung과 Yoo 2007). 한편, 황산 이온은 $\mathrm{Ag}_{2} \mathrm{SO}_{4}$ 의 $\mathrm{K}_{\mathrm{sp}}$ 가 $1.5 \times 10^{-5}$ 으로 $\mathrm{AgCl}\left(\mathrm{K}_{\mathrm{sp}}=1.8 \times 10^{-10}\right)$ 에 비해 매우 크 고(Harris 2010), 동일 분석 조건 하에서 최대 $10,000 \mathrm{ppm}$ 이 상 용해된 상태로 존재할 수 있는 것으로 계산되어 진다. 


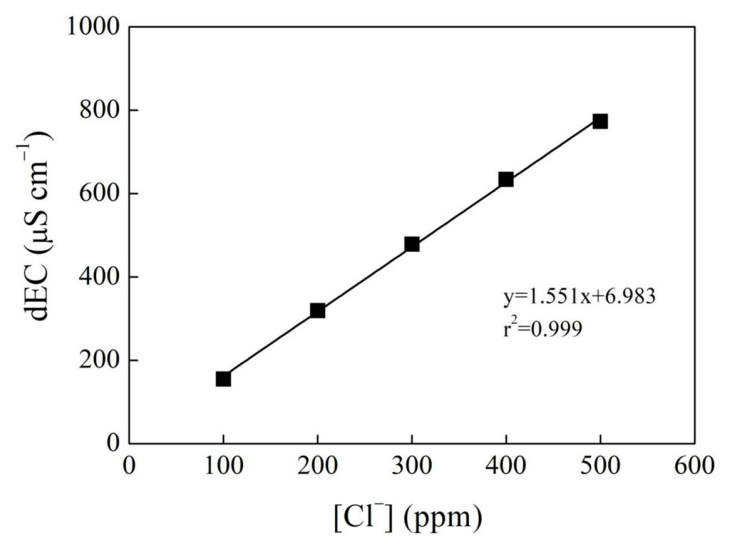

Fig. 1 Calibration curve of $\left[\mathrm{Cl}^{-}\right]$versus $\mathrm{dEC}$. When $\mathrm{AgNO}_{3}$ is added into the solution, $\mathrm{Cl}^{-}$precipitates out as $\mathrm{AgCl}$. $\mathrm{dEC}$ represents the difference in $\mathrm{EC}$ between before and after precipitation. $\mathrm{EC}$ of the added $\mathrm{AgNO}_{3}$ was taken into account for calculation of dEC. Error bars (representing standard errors, $n=3$ ) are smaller than the symbols

Table 2 Validation of Ag-dEC method for determination of $\mathrm{Cl}^{-}$

\begin{tabular}{cccc}
\hline \hline \multirow{2}{*}[\mathrm{Cl}^{-}]{$(\mathrm{ppm})$} & $\mathrm{n}$ & \multicolumn{2}{c}{${ }^{\mathrm{a}} \mathrm{dEC}\left(\mu \mathrm{S} \mathrm{cm}^{-1}\right)$} \\
\cline { 3 - 4 } & & Mean & $\mathrm{SD}$ \\
\hline 1.0 & 8 & 9.5 & 0.6 \\
10.0 & 8 & 26.4 & 0.3 \\
Method validation parameters & ${ }^{\mathrm{b}} \mathrm{DL}=2.6 \mu \mathrm{S} \mathrm{cm}^{-1}(1.1 \mathrm{ppm})^{\mathrm{c}}$ \\
& \multicolumn{3}{c}{$\mathrm{LOQ}=8.7 \mu \mathrm{S} \mathrm{cm}^{-1}(3.6 \mathrm{ppm})^{\mathrm{c}}$} \\
& ${ }^{\mathrm{d}}$ Precision $=1.7 \%$ \\
\hline
\end{tabular}

${ }^{\mathrm{a}} \mathrm{dEC}$ is EC difference of the solution between before and after precipitation of $\mathrm{Cl}^{-}$. $\mathrm{EC}$ of the added $\mathrm{AgNO}_{3}$ was taken into account for calculation of $\mathrm{dEC}$

${ }^{\mathrm{b}}$ Detection limit (DL) and level of quantification (LOQ) were evaluated from the SD of 8 replicated $\mathrm{dEC}$ values for $1.0 \mathrm{ppm}$ standard.

${ }^{c}$ The signal DL and LOQ were converted into respective ppm values using the calibration curve shown in Fig. 1

${ }^{\mathrm{d}}$ Precision was evaluated as the relative standard deviation of $\mathrm{dEC}$ values for $10.0 \mathrm{ppm}$ standard, which corresponds approximately to $10 \times \mathrm{DL}$

\section{분석 유효성: 검출한계, 정량한계 및 정밀도}

$\mathrm{Ag}-\mathrm{dEC}$ 법의 정량한계는 약 $3.6 \mathrm{ppm}$ 으로(Table 2), 이온 크로마 토그래피법의 통상적인 정량한계인 $0.1 \mathrm{ppm}$ 보다 높지만(MOE 2017), 평균 수천 $\mathrm{ppm}$ 이상의 $\mathrm{Cl}^{-}$농도를 보이는 염해지 $(\mathrm{Kim}$ 등, 2016)은 물론, 그 보다 낮은 수준의 일반 토양의 추출액에 대해서도 충분하다고 여겨진다. 아울러, 검출한계의 10 배 수준 에서 측정된 정밀도 역시 $2 \%$ 이하로 매우 양호하였다.

\section{염해토양 포화침출액의 $\mathbf{C l}^{-}$농도}

2016년 전남 고흥군 간척지 일원에서 채취된 토양의 포화침출 액의 $\mathrm{Cl}^{-}$농도는 $100-2,200 \mathrm{ppm}$ 의 범위를 보였으며, $\mathrm{Ag}-\mathrm{dEC}$ 법 과 이온 크로마토그래피의 분석결과는 서로 매우 잘 일치하였 다(paired $\mathrm{t}=0.004, p>0.995$ ). 따라서, $\mathrm{Ag}-\mathrm{dEC}$ 법이 가진 감도, 검량 구간, 정량한계, 정밀도 및 분석 적응성(analytical robustness) 은, 이 새 방법이 간척지와 같은 염해토양의 염도 분포 및 변화 도 모니터링에 유용한 대안이 될 수 있음을 보여준다. 아울러, 이온 크로마토그래프에 비해 상대적으로 저렴한 $\mathrm{EC}$ 메터로 분



Fig. 2 Comparison of measured $\left[\mathrm{Cl}^{-}\right]$in saturated paste extracts between Ag-dEC method and ion chromatography. The extracts were prepared using the soils collected from 17 different fields of reclamation tidal land in Goheung, southern Korea. The paired t test was used to find whether there is a significant difference between the methods

석이 가능할 뿐만 아니라, 신속하고 간편한 조작으로 많은 시료 들을 분석할 수 있는 장점이 있다. 따라서, 실험실 내 뿐만 아니 라, 현장에서 재빠르게 조사하는 목적으로도 활용이 기대된다.

\section{초 록}

염해토양에서 염소이온은 작물에 대한 독성이 가장 큰 음이온 이다. 일반적으로, 이온 크로마토그래피와 전위차 적정법 등 정 밀한 기기분석이 염소이온 분석에 이용되고 있으나, 본 연구에 서는 간단한 $\mathrm{EC}$ 메터를 이용해 신속히 그리고 비교적 정밀하 게 염해지 염소이온이 정량 가능하다는 것을 확인하였다. $\mathrm{Cl}^{-}$이 $\mathrm{AgCl}$ 로 침전될 때 수반되는 전기전도도 변화도 $(\mathrm{dEC})$ 는 염소이 온 농도와 매우 직선적인 비례 관계가 있었으며, 감도, 검량 구 간, 정량한계, 정밀도 및 분석 적응성 모두 양호한 것으로 조사 되었다. 또한, 이 $\mathrm{Ag}-\mathrm{dEC}$ 법으로 분석된 전남 고흥군 간척지 일 원 토양침출액의 염소이온 농도는 이온 크로마토그래피의 분석 결과와 매우 잘 일치하였다.

Keywords 다량 분석 - 방해이온 - 염해토양 - 은적정법 - 이온 크로마토그래피

감사의 글 본 연구는 2017년도 농촌진흥청 공동연구사업(PJ01221366)의 지원으로 수행되었습니다.

\section{References}

Boo H, Park J, Han GH (2015) Simple determination of chloride in soil solutions by $\mathrm{AgCl}$ precipitation. J Agr Sci Chungbuk Nat'l Univ 31(2): $183-188$

Frankenberger WT, Tabatabai MA, Adriano DC, Doner HE (1996) Bromine, chlorine, fluorine. In: Sparks DL (ed) Methods of Soil Analysis Part 3Chemical Methods, Soil Science Society of America, Madison

Harris D (2007) Statistics. Quantitative chemical analysis, 7th edn. W. H. Freeman, New York 
Harris D (2010) Chemical equilibrium. Quantitative chemical analysis, 8th edn. W. H. Freeman, New York

Herrero J, Weindorf DC, Castañeda C (2015) Two fixed ratio dilutions for soil salinity monitoring in hypersaline wetlands. PLoS ONE. doi:10.1371/ journal.pone.0126493

Jung YS, Yoo CH (2007) Soil problems and agricultural water management of the reclaimed land in Korea. Korean J Soil Sci Fert 40(4): 330-348

Kim YJ, Ryu JH, Lee SH, Oh YY, Kim S, Jung J, Hong HC, Kim YD, Kim SL (2016) Spatio-temporal distribution characteristics of the soil salinity in Saemangeum Gyehwa newly reclaimed land. J Korean Soc Int Agric 28(1): 113-117

Lee YJ, Lee JS, Yang JE (2010) The comparison of electrical conductivity for soil solutions extracted in field capacity and saturation-paste. Korean J Soil Sci Fert 43(6): 776-781

Lee YJ, Yun HB, Kim RY, Lee JS, Song YS, Sung JK, Yang JE (2012) Determination of exchangeable cations in soils affected by different types of salt accumulation. Korean J Soil Sci Fert 45(2): 135-142

Leland E, Eugene V (1999) Crop response and management of salt-affected soils. In: Pessarakli M (ed) Handbook of plant and crop stress, 2nd edn. CRC Press, Boca Raton

MOE (2017) Official methods for the water qualities. Ministry of Environment Official Announcement 2017-4, Sejong
NIAST (2000) Methods of analysis of soil and plant. National Institute of Agricultural Science and Technology, Suwon

Rengasamy P (2006) World salinization with emphasis on Australia. J Exp Bot 57(5): 1017-1023

Rengasamy P (2010) Soil processes affecting crop production in salt-affected soils. Funct Plant Biol 37: 613-620

Rhoades JD (1996) Salinity: electrical conductivity and total dissolved solids. In: Sparks DL (ed) Methods of Soil Analysis Part 3-Chemical Methods, Soil Science Society of America, Madison

Tabatabai MA, Frankenberger WT (1996) Liquid chromatography. In: Sparks DL (ed) Methods of Soil Analysis Part 3-Chemical Methods, Soil Science Society of America, Madison

Tavakkoli E, Rengasamy P, Mcdonald GK (2010) High concentrations of $\mathrm{Na}^{+}$ and $\mathrm{Cl}^{-}$ions in soil solution have simultaneous detrimental effects on growth of faba bean under salinity stress. J Exp Bot 61(15): 4449-4459

White PJ, Broadley MR (2001) Chloride in soils and its uptake and movement within the plant: a review. Ann Bot-london 88: 967-988

Wong VN, Greene RSB, Dalal RC, Murphy BW (2010) Soil carbon dynamics in saline and sodic soils: a review. Soil Use Manage 26: 2-11

Xu G, Magen H, Tarchitzky J, Kafkafi U (1999) Advances in chloride nutrition of plants. Adv Agron 68: 97-150 